Research Article

\title{
Investigation of Ground Vibration of Full-Stone Foundation under Dynamic Compaction
}

\author{
Jiawen Wu, ${ }^{1}$ Linjian Ma $\mathbb{D}^{1},{ }^{1}$ Jun Shi, ${ }^{2}$ Yangyang Sun $\mathbb{D}^{\circ},{ }^{3}$ Jiewei Ke, ${ }^{4}$ and Dan Wang ${ }^{3}$ \\ ${ }^{1}$ State Key Laboratory of Disaster Prevention \& Mitigation of Explosion \& Impact, Army Engineering University of PLA, \\ Nanjing 210007, China \\ ${ }^{2}$ Engineering Agent Management Office of Logistics Department of PLA Navy, Beijing 100036, China \\ ${ }^{3}$ College of National Defense Engineering, Army Engineering University of PLA, Nanjing 210007, China \\ ${ }^{4}$ Unit 31619 of PLA, Nanjing 211131, China
}

Correspondence should be addressed to Linjian Ma; patton.4400@163.com

Received 17 June 2019; Revised 18 July 2019; Accepted 3 September 2019; Published 24 October 2019

Academic Editor: Laurent Mevel

Copyright (c) 2019 Jiawen Wu et al. This is an open access article distributed under the Creative Commons Attribution License, which permits unrestricted use, distribution, and reproduction in any medium, provided the original work is properly cited.

\begin{abstract}
This study focuses on the ground vibration of a full-stone foundation treatment project. The single-point dynamic compaction test was performed using a tamping machine at an energy level of $3200 \mathrm{kN} \cdot \mathrm{m}$. Time-history curves of ground vibration velocity were recorded under 10 times tamping within $120 \mathrm{~m}$ distance. The effects of tamping times on the waveform of velocity and frequency spectra were assessed, as well as of peak ground velocity (PGV), peak ground acceleration (PGA), and average frequency. Furthermore, the attenuations of PGV, PGA, and average frequency were also analyzed in detail. It has been founded that increasing tamping times of dynamic compaction can effectively improve PGV and PGA. For the frequency spectra, the increasing tamping times contribute to a higher frequency range, more primary frequencies, and a larger frequency domain. However, the three parameters, namely, PGV, PGA, and average frequency, remain stable roughly when they reach a threshold of test tamping times. The attenuations of PGV and PGA with the proportional distance follow the power law with negative exponents. Furthermore, the fitted equivalent factor increases while the damped exponential decreases persistently with the increase of tamping times. The average frequency is negatively linearly correlated with the proportional tamping distances.
\end{abstract}

\section{Introduction}

Dynamic compaction is a widely used foundation treatment technique which takes full advantage of huge kinetic energy from dropping a heavy hammer to densify the foundation and satisfy the settlement requirements in engineering. It is well established that dynamic compaction can not only effectively reduce the compressibility of foundation and enhance its strength but also can improve the antivibration liquefaction ability and eliminate the collapsibility. The mechanism lies in generating a wave field in the foundation under impact compaction, which consists of the body wave (longitudinal wave and transverse wave) and surface wave (Rayleigh wave and Love wave) [1]. Rock-soil skeleton is disintegrated by the tension and compression of the longitudinal wave. Furthermore, the loose grains are interlocked and compacted by the shear action of the transverse wave that arrives later [2]. Normally, the dropping of a hammer with a weight of $15 \sim 20 \times 10^{3} \mathrm{~kg}$ from a height of $18 \sim 23 \mathrm{~m}$ can remarkably improve the mechanical properties of soil foundation within a range of 9 12 $\mathrm{m} \mathrm{[3].}$ However, the surface wave induced by the dynamic compaction may damage the surrounding buildings, precise equipment, as well as affect the lives of residents. Therefore, it is necessary to monitor the ground vibration in dynamic compaction activity to evaluate the safety of the construction scheme reasonably.

It is widely accepted that the ground vibration parameters, such as the peak ground velocity (PGV), peak ground acceleration (PGA), and Fourier spectra are severely affected by geological and topographic factors [4], while vibration intensity is closely related to the energy of the vibration 
source and the distance from it [5]. According to statistical data [6], the damages on ground structures are mainly correlated with the vibration velocity, followed by acceleration. As the tamping time increases, the ground vibration velocity increases significantly [3], as well as the inertial force on the ground structure induced by vibration acceleration [7]. Hence, the vibration safe distance is generally determined by controlling PGV and PGA. Vibration intensity gradually attenuates with the increase of the distance. Gutowski and Dym [8] found that ground vibration amplitude induced by Rayleigh wave and the tamping distance follows a negative power function, which was validated by a great number of engineering tests. Auersch and Said [9] further investigated the attenuation of ground vibrations due to different technical sources. Besides, the relevant characteristics like frequency of the ground vibration are of vital importance for response level and damage probability, which may serve as an effective supplement in the evaluation of vibration hazards induced by dynamic compaction [5]. The waves induced by dynamic compaction construction are featured by low frequency and transiency, the principle of which is basically identical to that of earthquake vibration [10]. Soil field test results demonstrate that peak frequency of particle velocity under dynamic compaction is around $2 \sim 20 \mathrm{~Hz}$ [11-13]. For gray silty sand and silty clay foundation, Hwang et al. [14] stated that radial vibration duration is longer than vertical vibration duration; primary frequency of vertical vibration ranges from 10 to $20 \mathrm{~Hz}$, while radial vibration contains two primary frequency range of $3 \sim 4 \mathrm{~Hz}$ and $13 \sim 14 \mathrm{~Hz}$. Therefore, the effects of vibration on the nearby structures can be estimated by analyzing peak intensity, Fourier frequency spectra, and vibration attenuation comparing with the corresponding specified limits.

Generally, ground vibration induced by dynamic compaction exhibits different propagation rules under different geological conditions [15]. In particular, the investigations have been rarely devoted to the vibration rules of full-stone foundation. Based on a foundation treatment project, this study conducted single-point dynamic compaction tests on a full-stone foundation (mainly composed of andesites) at an energy level of $3200 \mathrm{kN} \cdot \mathrm{m}$. The vibration velocity waveforms in radial and vertical directions and the Fourier frequency spectra were analyzed under 10-time repeated tamping in dynamic compaction tests. Moreover, the effects of tamping time on PGV, PGA, and average frequency, as well as the amplitude attenuation with distance, were examined. The results may provide insightful reference for ensuring safety in dynamic compaction construction.

\section{Description of Project and Ground Conditions}

The foundation reinforcement projects are located in a mountainous area of China including blasting peak cutting, depression backfilling, and dynamic compaction. The complex geological and topographic conditions raise a challenge for rock-soil and full-stone foundations' compaction in this mountain area. After dynamic compaction, the bearing capacity and deformation modulus of all foundations should be higher than $200 \mathrm{kPa}$ and $16 \mathrm{MPa}$, respectively. In this test area, the engineering purpose mainly aims at full-stone foundation reinforcement. The project site was filled with the $5 \mathrm{~m}$-thick moderate weathering andesite, originating from the blasting mountain. The dry uniaxial compressive strength of the andesite is $73.07 \sim 155.54 \mathrm{MPa}$, the saturated uniaxial compressive strength is $33.08 \sim 120.56 \mathrm{MPa}$, and the elastic modulus is 27.94 54.50 GPa. The diameters of filled stone are smaller than $0.81 \mathrm{~m}$ and most are in the range of $0.14 \mathrm{~m} \sim 0.42 \mathrm{~m}$, and the uniform coefficient exceeds 10. The bedrock is undisturbed andesite. In the tested region, a cast steel rammer with a bottom diameter of $2.5 \mathrm{~m}$ was used for dynamic compaction. Figure 1 presents the layout in the tested region and the surrounding construction. The distance between the simple road and tamping point is $122 \mathrm{~m}$.

There are many important facilities and precise devices located in the range $80 \sim 130 \mathrm{~m}$ from the dynamic compaction region; the ground vibration during dynamic compaction should be monitored to predict the damage potential.

\section{Vibration Monitoring}

3.1. Instrument and Equipment. The equipment for measuring ground vibration consists of three-component geophones (CDJ-S2C), piezoelectric accelerometers (CA-YD159), recording and storing devices, and connectable electric cables. The three-component geophone, developed by Chongqing Geological Instrument Plant, China, was used for monitoring ground vibration velocity with a frequency range of $2 \sim 500 \mathrm{~Hz}$, a sensitivity of $200 \pm 10 \% \mathrm{~V} / \mathrm{m} / \mathrm{s}$, and a harmonic distortion smaller than $0.2 \%$. The measurement range of acceleration is $\pm 1 \mathrm{~g}$. The sensitivity and resolution of the acceleration sensor is $10 \mathrm{~V} / \mathrm{g}$ and $2 \times 10^{-5} \mathrm{~g}$, respectively. The resolution of the A/D interface is 16-bit, and the recording precision can reach up to $0.01 \mathrm{~cm} / \mathrm{s}$ with a sampling frequency of $8000 \mathrm{~Hz}$. The acquisition device can display lots of information including waveform, maximum value, and frequency immediately after sampling. The vibration sensors were fixed by land plaster and an appropriate amount of water in the monitoring test.

3.2. Arrangement of Measuring Points. In order to assess the effects of single tamping of the dynamic compaction on the surrounding facilities, six measuring points were arranged on the ground for recording the vibration signal in the distance within $120 \mathrm{~m}$ with a spacing of $20 \mathrm{~m}$, as shown in Figure 2 . The measuring path was led out from the tamping center and perpendicular to the road line. The dump-filling thickness of stones is $4 \sim 5 \mathrm{~m}$ in the test site. The foundation ground of nearby facilities including $E-1, E-2$, and $E-3$ in Figure 1 is generally consistent to that of the sensor arrangement region. However, the region from the dynamic compaction area to the facility $F-1$ was filled with $5 \sim 8.5 \mathrm{~m}$ moderate weathering andesite mixed with silty sand. Its original foundation has complex topography with numerous gullies, as well as different geotechnical conditions. Besides, 


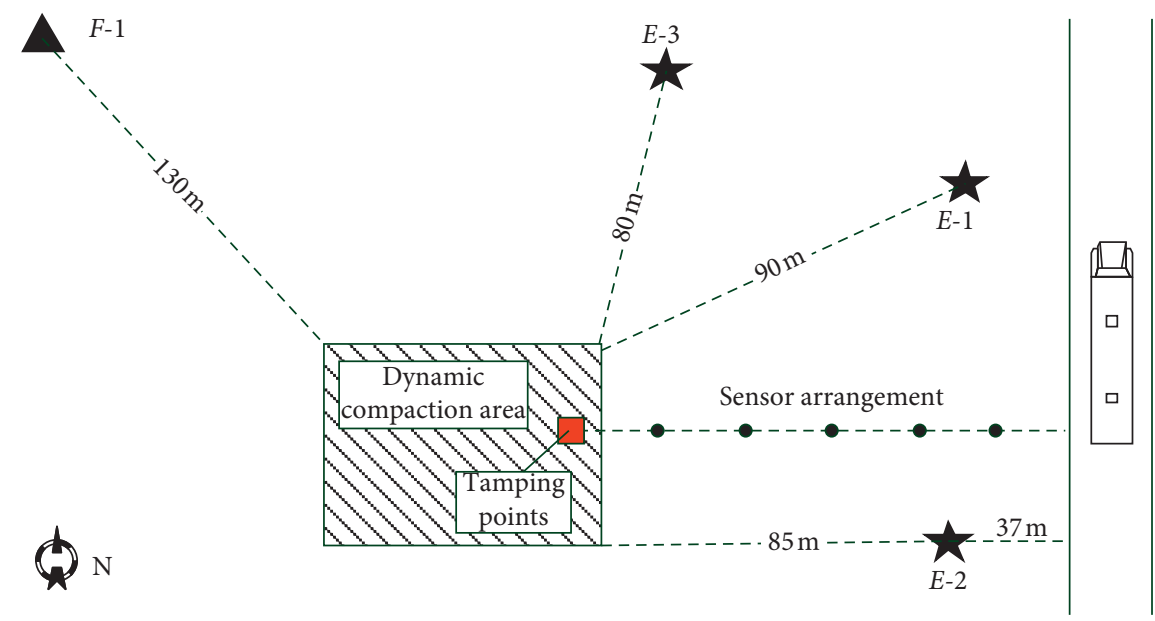

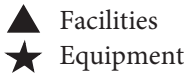

FIgURE 1: Layout of the plant and the arrangement of velocity sensors in the tested area.

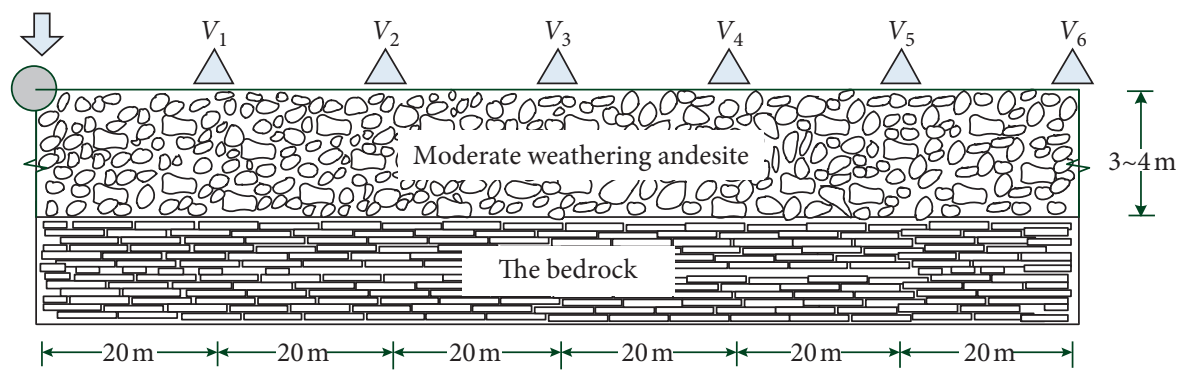

$3200 \mathrm{kN} \cdot \mathrm{m}$

FIgURE 2: Arrangement of dynamic compaction velocity sensors (unit: $\mathrm{m}$ ).

considering the strong seismic performance of the facility $F$ 1 and long distance to the dynamic compaction area, the impact of dynamic compaction on facility $F-1$ is much smaller than that of other equipment, which can be neglected.

\section{Results and Discussion}

4.1. Vibration Velocity Waveform. Figure 3 presents the waveforms of three directions' vibration velocity at $V_{4}$ monitoring point ( $80 \mathrm{~m}$ distance) subjected to 9th tamping with a standard energy of $3200 \mathrm{kN} \cdot \mathrm{m}$. As seen in Figure 3, the initial oscillation time of radial velocity is similar to that of vertical velocity, while the peak velocity in the vertical direction appears first. The significant attenuations of radial and vertical velocities take on at the time of 0.23 and $0.19 \mathrm{~s}$, i.e., the peak velocity of -0.41 and $-0.31 \mathrm{~cm} / \mathrm{s}$, respectively. However, the tangential vibration velocity is in the range of $-0.07 \sim 0.08 \mathrm{~cm} / \mathrm{s}$ and that waveform is complex. In this regard, this study only examined ground vibrations in the radial and vertical directions.

Figures 4 and 5 show radial and vertical vibration velocity histories at $80 \mathrm{~m}$ distance under different tamping times. It can be seen from Figure 4 that the radial vibration velocity gradually reaches its maximum value at $0.27 \mathrm{~s}$ after 9

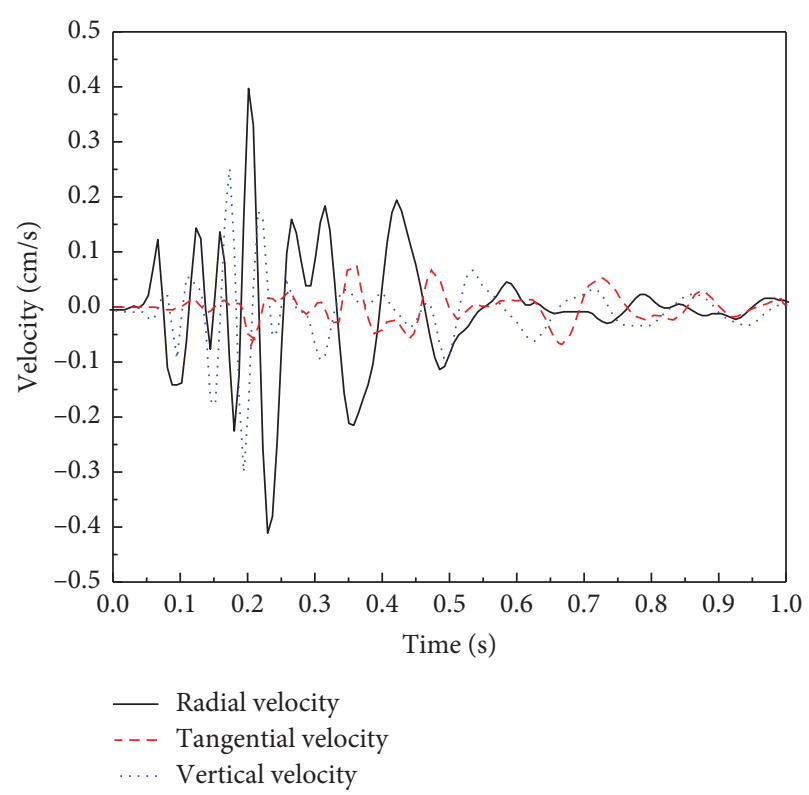

FIGURE 3: Waveforms of vibration velocity at $80 \mathrm{~m}$ distance.

tampings. The amplitude began to attenuate significantly at $0.47 \mathrm{~s}$, and the time of radial vibration lasts approximately $0.75 \mathrm{~s}$. The radial vibration velocity keeps similar waveforms 

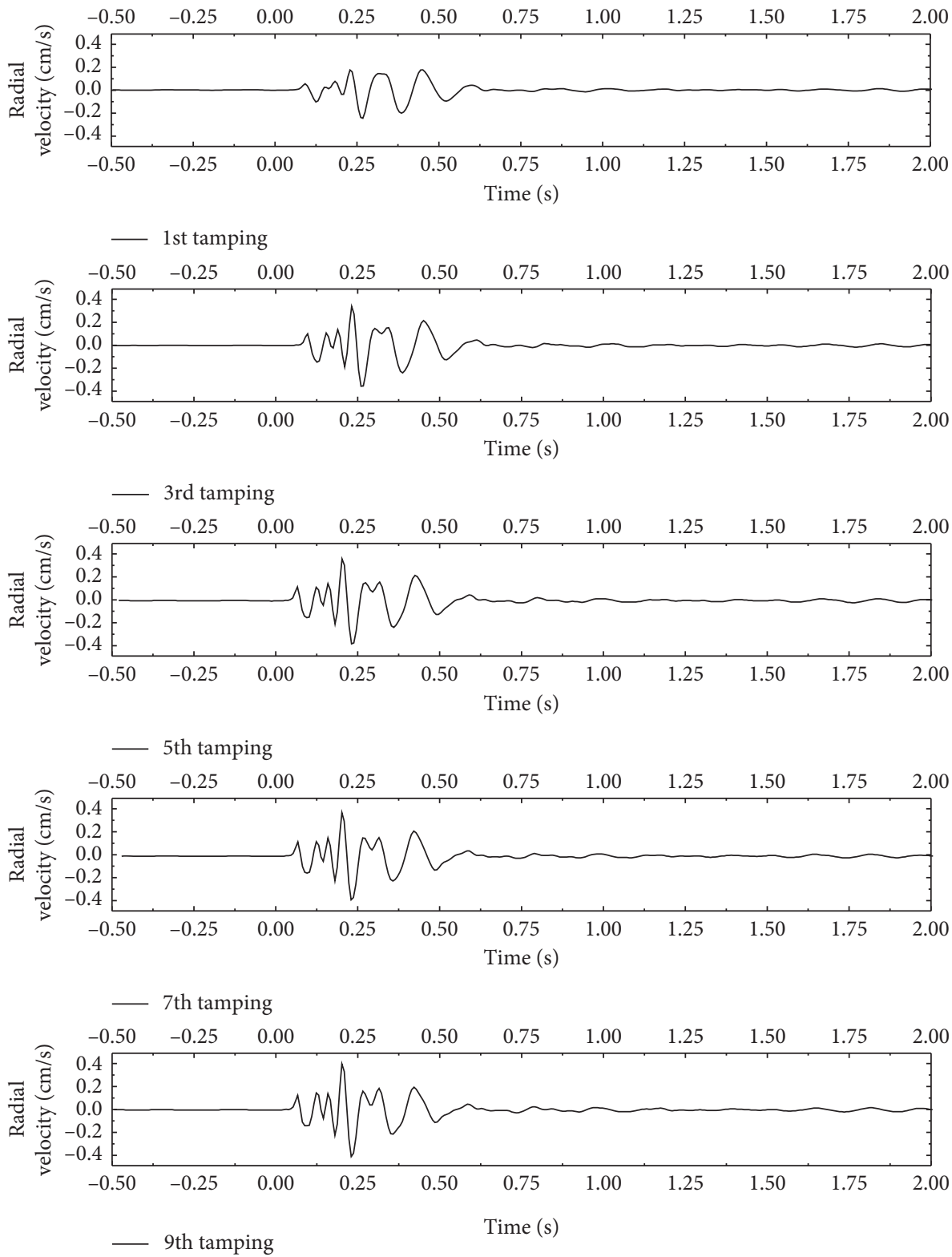

Figure 4: Radial vibration velocity histories at $80 \mathrm{~m}$ distance under different times of tamping.

under different tamping times but only at slightly different amplitudes. As shown in Figure 5, the vertical vibration velocity reaches its maximum value at $0.2 \mathrm{~s}$ followed by the periodic attenuation since $0.5 \mathrm{~s}$, and vibration lasts approximately $1 \mathrm{~s}$. Similarly, vertical vibration velocity waveforms are generally not affected by tamping times except for slightly different amplitudes.

Table 1 lists the occurrence time of radial and vertical PGV at an $80 \mathrm{~m}$ distance. Overall, the radial and vertical PGV appear earlier with the increase of tamping times. However, after 7 tampings, the occurrence time of PGV tends to be stable. After 9 tampings, the presence moments of radial and vertical PGV are eventually shortened by $0.038 \mathrm{~s}$ and $0.020 \mathrm{~s}$, respectively. The tamping energy is mainly consumed by the compressive deformation of rock foundation at the beginning of impact compaction, thereby leading to smaller vibration velocity. As the tamping time increases, full-stone foundation is gradually compacted. So, the PGV increases continuously and the corresponding occurrence time is shortened until the full-stone foundation remains stable roughly.

\subsection{PGV Monitoring}

4.2.1. Effect of Tamping Time on PGV. Figure 6 depicts the relationships between $\mathrm{PGV}$ and tamping time at different directions and distances. As shown in Figure 6, both radial and vertical PGV increase with the increasing of tamping times but negatively correlated with the measured distance. The radial PGV increases by $12.27 \%$ after 3 tampings at $20 \mathrm{~m}$ distance, while the increasing amplitude of the vertical PGV is as high as $67.80 \%$ after 4 tampings. Afterwards, both radial and vertical PGV approximately remain stable despite small 

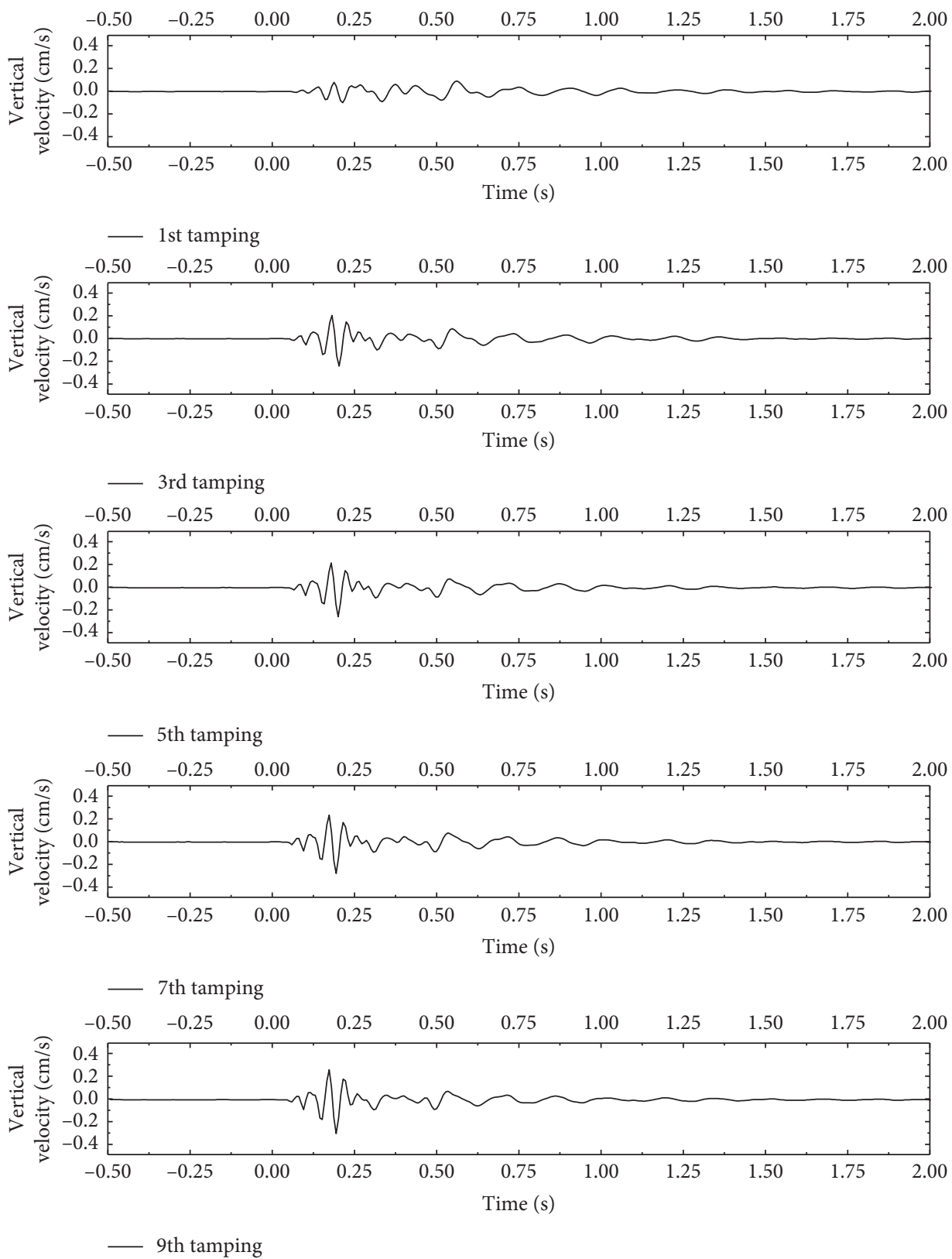

FIgURE 5: Vertical vibration velocity histories at $80 \mathrm{~m}$ distance under different times of tamping.

TABLE 1: Occurrence time of PGV at $80 \mathrm{~m}$ distance.

\begin{tabular}{lccccc}
\hline Direction & 1st tamping & 3rd tamping & 5th tamping & 7th tamping & 9th tamping \\
\hline Radial direction & $0.268 \mathrm{~s}$ & $0.260 \mathrm{~s}$ & $0.231 \mathrm{~s}$ & $0.230 \mathrm{~s}$ & $0.230 \mathrm{~s}$ \\
Vertical direction & $0.214 \mathrm{~s}$ & $0.203 \mathrm{~s}$ & $0.200 \mathrm{~s}$ & $0.194 \mathrm{~s}$ & $0.194 \mathrm{~s}$ \\
\hline
\end{tabular}

fluctuations. It is noted that the vibration velocity increases slightly after 9 tampings. This lies in the fact that the stone foundation is crushed and re-interlocked in the impulse wave field after multiple tampings. Overall, the increasing tamping time plays a positive role in enhancing the foundation characteristics. After 4 tampings, the mechanical properties of the rock foundation were significantly enhanced. After 9 tampings, the vibration velocity of the foundation basically remains stable. It is obvious that the vibration induced by 9 continuous tampings may impose the greatest damage to nearby structures.

4.2.2. Effect of Measured Distance on PGV. Vibration intensity generally undergoes attenuation with distance, which is mainly attributed to geometrical damping and material damping [5]. The geometrical damping means that while the wave propagates far from the vibration source, the wavefront 


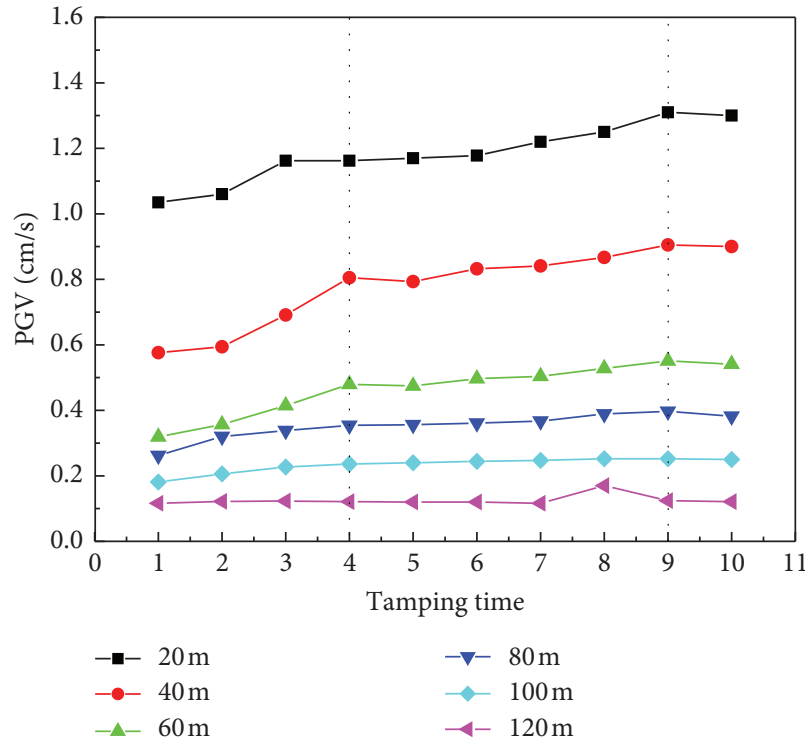

(a)

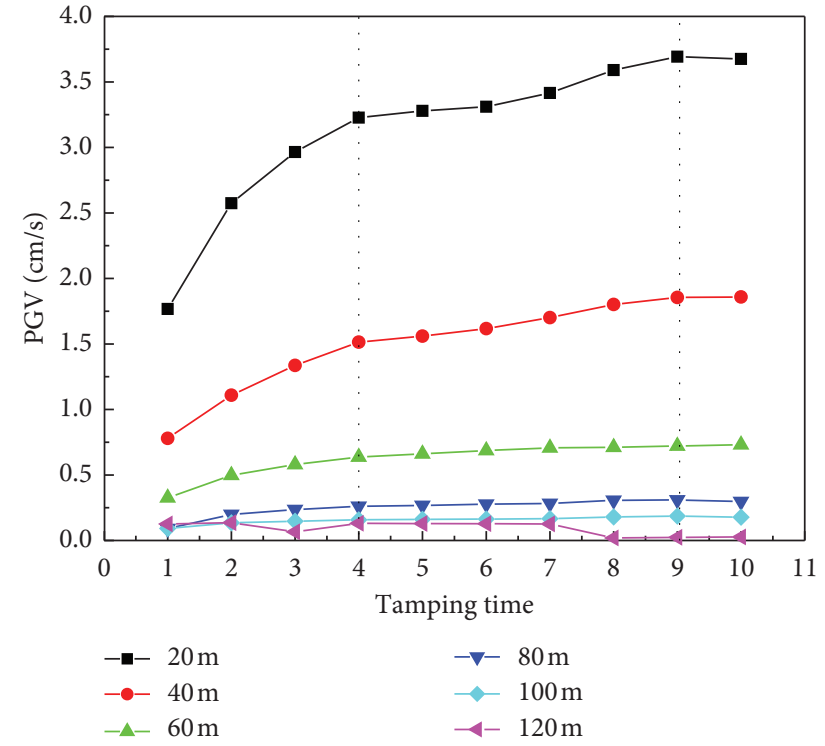

(b)

FIGURE 6: Relations between PGV and tamping times at different measured distances. (a) In radial direction. (b) In vertical direction.

expands and its energy density decreases with distance, resulting in the decline of vibration amplitude. Geometrical damping is affected by the vibration waveform and wavefront shape. The material damping refers to the energy dissipation as the wave travels through the rock-soil layer, which depends on the soil type, moisture content, and temperature, and so on [16].

Figure 7 illustrates the attenuation of radial and vertical PGV with the proportional distance subjected to odd time tamping. The proportional tamping distance is defined as $\bar{R}=R / \sqrt[3]{Q}$, where $R$ denotes the distance from the tamping point and $Q=3.2 \times 10^{6} \mathrm{~J}$. When the proportional distance is smaller than 0.40 , the PGV decreases rapidly with distance. Specifically, the radial PGV decreases by $60.75 \%$ 69.23\%, while the attenuation of PGV in the vertical direction is as high as $79.32 \% \sim 83.67 \%$. As the proportional distance exceeds 0.40 , both radial and vertical PGV values become relatively smaller. The attenuation law of the vibration intensity with distance can be fitted by the following power function with a negative exponent [17]:

$$
\left\{\begin{array}{l}
\mathrm{PGV}_{1}=k_{1} \bar{R}^{-\alpha_{1}}, \\
\mathrm{PGV}_{2}=k_{2} \bar{R}^{-\alpha_{2}},
\end{array}\right.
$$

where $k$ denotes the equivalent factor and $\alpha$ denotes the damped exponential. Subscripts 1 and 2 denote radial direction and vertical direction, respectively. Table 2 lists the fitted values of $k$ and $\alpha$ in equation (1).

As shown in Table 2, the attenuation of PGV with the increase of proportional distance is reasonably fitted by the power function with negative exponents. As the tamping time increases, the equivalent factor increases and damped exponential decreases, which is on account of the energy dissipation decreasing as the rock layer becomes denser. Besides, the damped exponential of radial PGV is smaller than that of the vertical direction, implying that more energy is consumed during ground vibration in vertical vibration than that in radial direction. For gray silty sand foundation [14], the 9-time-tamping average of PGV in radial and vertical directions decreases $93.91 \%$ and $88.26 \%$ at a distance of $20 \mathrm{~m}$ to $80 \mathrm{~m}$, respectively. The attenuation ratio of fullstone foundation's radial PGV, $67.10 \%$, is obviously lower than the gray silty sand foundation. However, the vertical attenuation ratio of the two-type foundation is basically within $88.26 \% \sim 91.69 \%$. It indicates that the radial energy transmission capacity of the full-stone foundation is higher than that of the gray silty sand foundation, which poses a potential threat to buildings and people's lives.

\subsection{PGA Monitoring}

4.3.1. Effect of Tamping Time on PGA. Figure 8 presents the relations between PGA and tamping times at different measured distances. The effect of tamping time on PGA is similar to that on PGV. The relationship curves can be divided into three phases. After 4 tampings, the PGA at a tamping distance of within $40 \mathrm{~m}$ increased significantly. For example, the PGA of ground vibration increased by $42.23 \%$ at a tamping distance of $20 \mathrm{~m}$. The PGA at a tamping distance below $100 \mathrm{~m}$ increased slowly during the next 4-5 tampings. After 9 tampings, the foundation was compacted and the radial PGA was nearly doubled at $20 \mathrm{~m}$ from the tamping point. It is needed to point out that the PGA at $120 \mathrm{~m}$ from the tamping point remained approximately $0.01 \mathrm{~g}$ during the whole tamping process, which seemed unaffected by the increase of tamping times. This suggests that the point at the distance of $120 \mathrm{~m}$ has already exceeded the effective tamping range.

Vertical PGA exhibits a similar variation rule with the increase of tamping times except for far greater variation amplitude. Additionally, the vertical PGA was more 


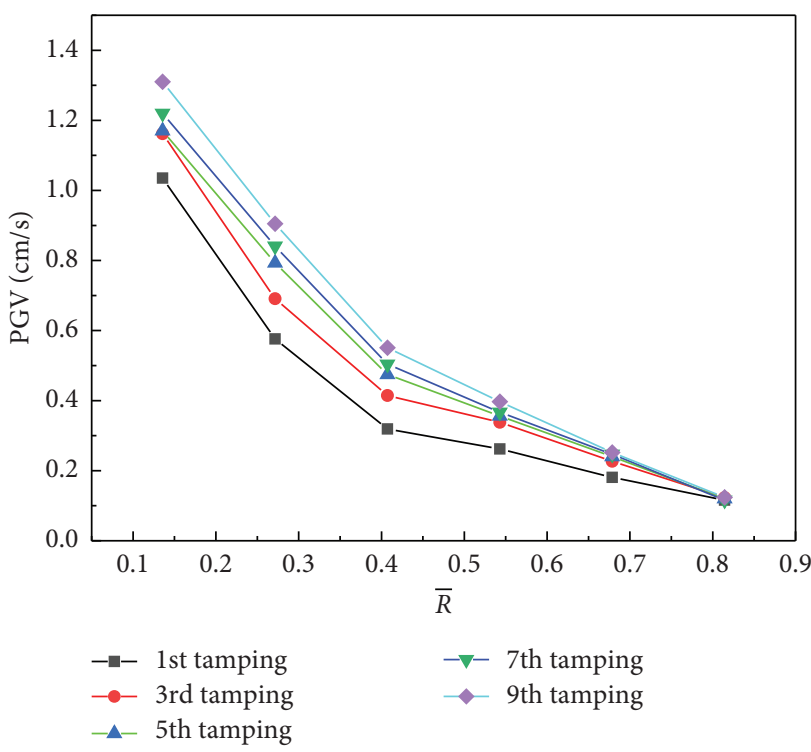

(a)

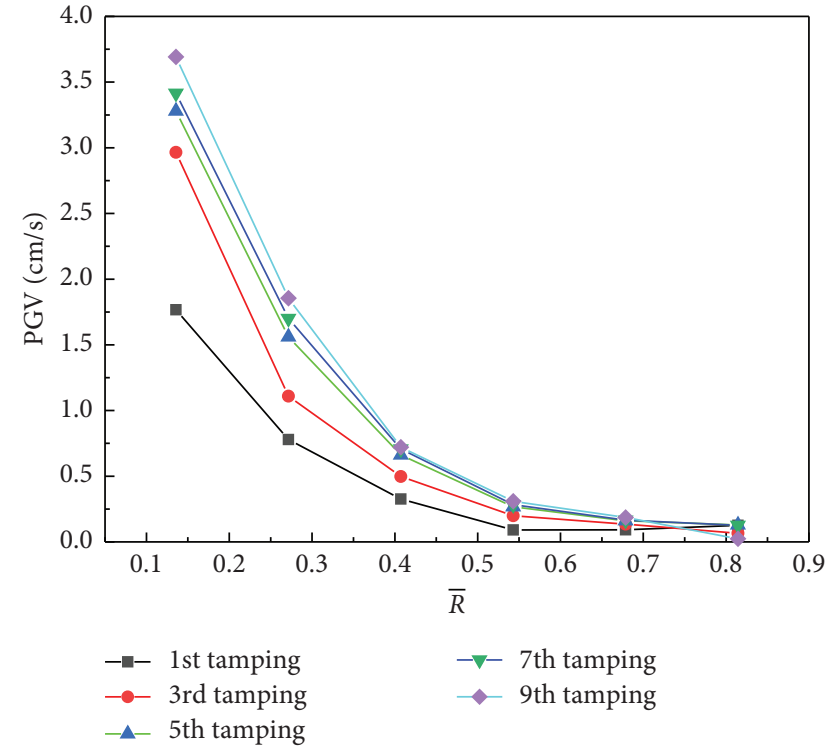

(b)

Figure 7: Attenuation of PGV with distance under different tamping times. (a) In radial direction. (b) In vertical direction.

TABLE 2: Attenuation parameters of PGV under odd time tamping.

\begin{tabular}{lcccccc}
\hline \multirow{2}{*}{ Time } & \multicolumn{7}{c}{ Parameters } \\
& $k_{1}$ & $\alpha_{1}$ & $R^{2}$ & $k_{2}$ & $\alpha_{2}$ & $R^{2}$ \\
\hline 1 & 0.13 & 1.02 & 0.98 & 0.09 & 1.53 & 0.97 \\
3 & 0.17 & 0.96 & 0.97 & 0.11 & 1.49 & 0.99 \\
5 & 0.20 & 0.90 & 0.94 & 0.19 & 1.42 & 0.97 \\
7 & 0.21 & 0.90 & 0.93 & 0.21 & 1.40 & 0.96 \\
9 & 0.23 & 0.90 & 0.92 & 0.21 & 1.40 & 0.95 \\
\hline
\end{tabular}

dependent on the distance from the tamping point. After 10 tampings continually, the PGA at the tamping distance of $20 \mathrm{~m}$ was up to $0.618 \mathrm{~g}$, while the PGA at the tamping distance range of 100 120 $\mathrm{m}$ was consistently lower than $0.02 \mathrm{~g}$. Therefore, it can be concluded that the dynamic compaction almost has no effects at the distance over $100 \mathrm{~m}$ from the tamping point.

4.3.2. Effect of Measured Distance on PGA. In order to investigate the attenuation law of PGA with distance subjected to different tamping times, the tested data under odd times of tamping were selected for plotting the relations of radial and vertical PGA with distance, as shown in Figure 9. It can be observed that both radial and vertical PGA declined rapidly at a proportional tamping distance below 0.4. Specifically, the attenuation amplitudes of radial and vertical PGA were $62.13 \% \sim 75.37 \%$ and $82.32 \% \sim 86.75 \%$, respectively. The attenuations of both radial and vertical PGA may be fitted by the following power function with negative exponents:

$$
\left\{\begin{array}{l}
\mathrm{PGA}_{3}=k_{3} \bar{R}^{-\alpha_{3}}, \\
\mathrm{PGA}_{4}=k_{4} \bar{R}^{-\alpha_{4}}
\end{array}\right.
$$

where $k$ denotes the equivalent factor and $\alpha$ denotes the damped exponential. The subscripts 3 and 4 denote radial and vertical directions, respectively. Table 3 summarizes the fitted values of $k$ and $\alpha$ according to equation (2).

It can be seen from Table 3 that the fitted equivalent factors increase with the increase of the tamping times, while the damped exponents are negatively correlated with the tamping times. Moreover, the damped exponential of vertical PGA is greater than that of radial PGA, that is, the vertical vibration decays more rapidly than radial vibration. This is similar to the attenuation of PGV as described in Section 4.2.2. The ground vibration along the vertical direction consumes more energy than that along the radial direction.

4.4. Fourier Spectra. The vibration frequency components and frequency domain range may serve as important bases for evaluating the safety of the equipment and buildings. By performing Fourier transform (FFT) on the records of ground variation in radial and vertical directions at a typical tamping distance of $80 \mathrm{~m}$ under 10 tampings, the Fourier amplitude spectrum of vibration velocities was calculated along radial and vertical directions. Figure 10 presents the Fourier amplitude spectrum at $80 \mathrm{~m}$ from the tamping point subjected to odd time tamping.

It can be seen in Figure 10 that the radial and vertical Fourier amplitude spectrums exhibit similar shapes. With an increase of tamping times, the Fourier amplitude spectra contain more wider frequency bands and higher amplitudes. This is attributed to the decline in tamping energy dissipation after multiple reflections and diffractions of the stress wave among rock layers [16]. As shown in Figure 10(a), the radial vibration frequency mainly ranges from $3 \mathrm{~Hz}$ to $42 \mathrm{~Hz}$, and the two primary frequencies are in the ranges of $6 \sim 10 \mathrm{~Hz}$ and $13 \sim 22 \mathrm{~Hz}$. Amplitudes at $13 \sim 22 \mathrm{~Hz}$ are strongly influenced by the increase of 


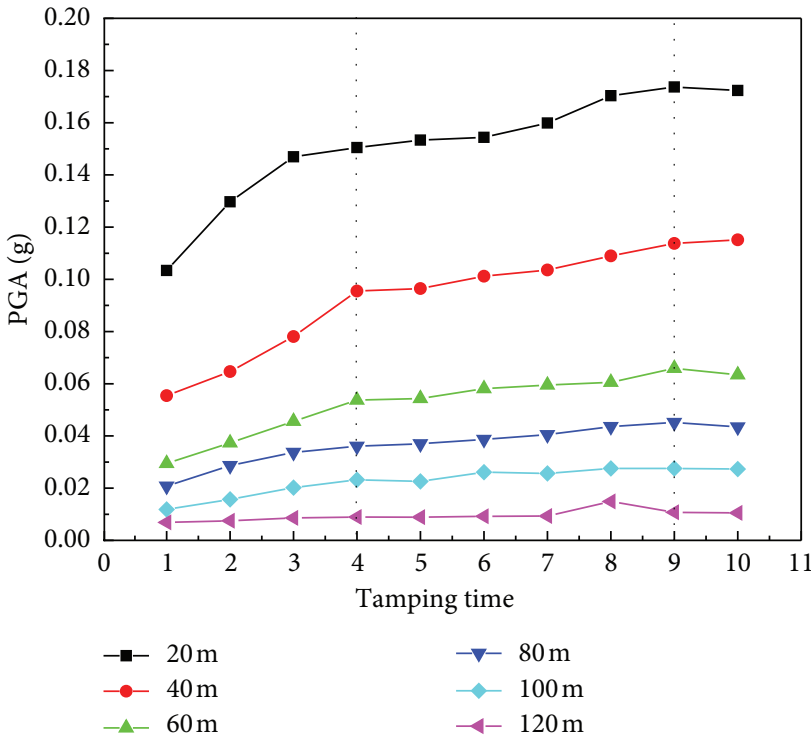

(a)

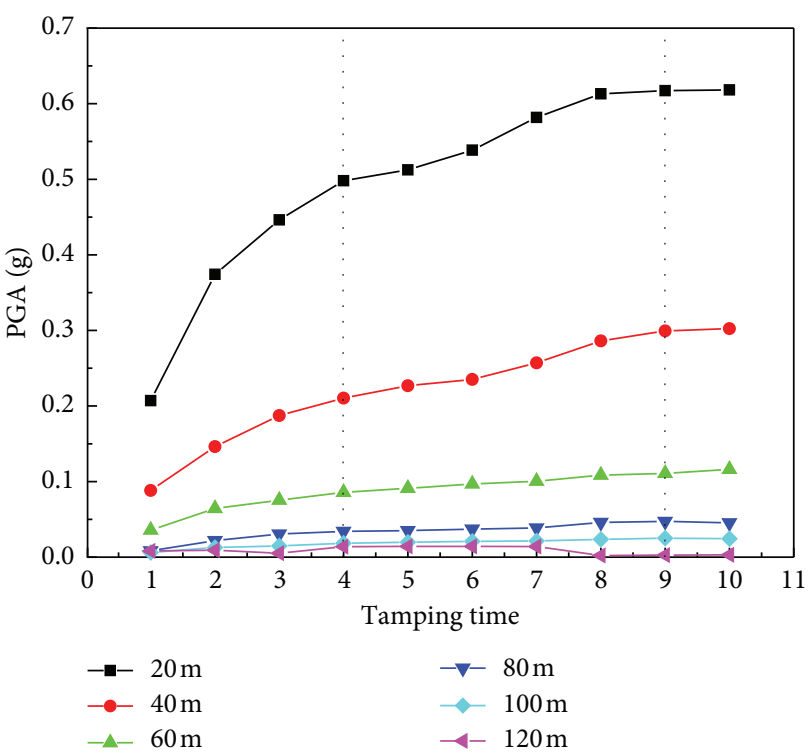

(b)

FIgUre 8: Relations between PGA and tamping time at different measured distances. (a) In radial direction. (b) In vertical direction.

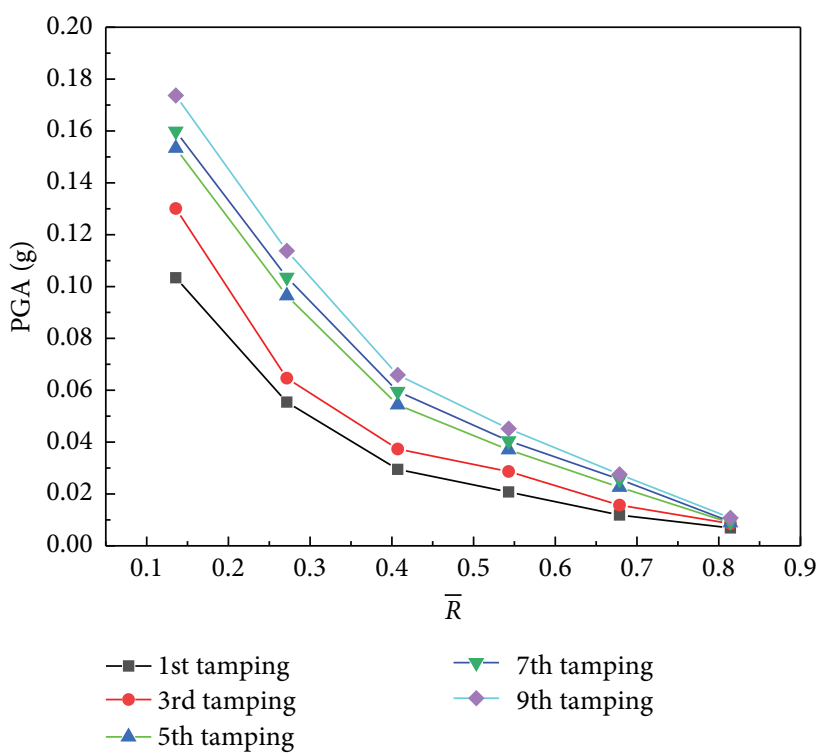

(a)

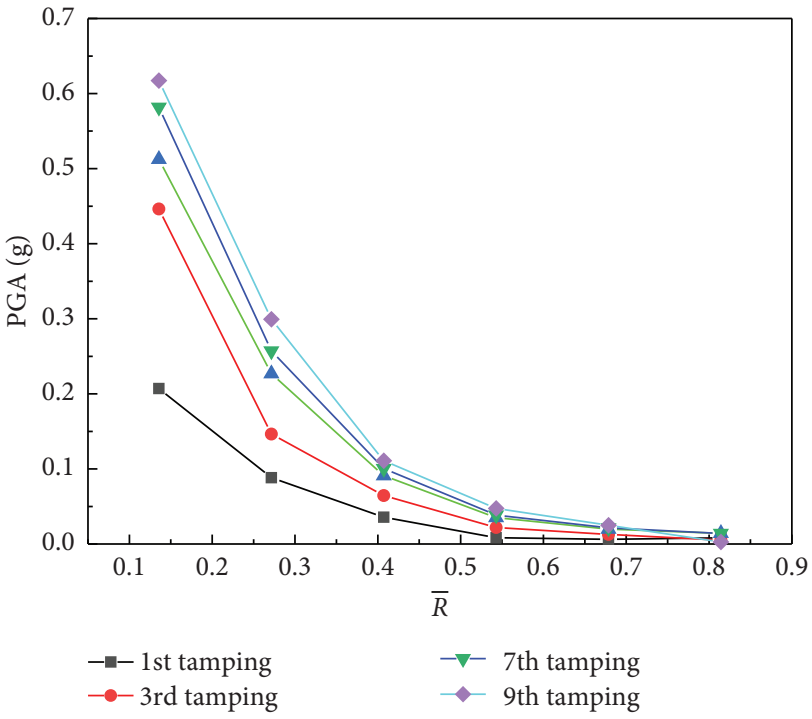

(b)

FIgURE 9: Attenuation of PGA with distance under different times of tamping. (a) In radial direction. (b) In vertical direction.

TABLe 3: Attenuation parameters of PGA under odd time tamping.

\begin{tabular}{lcccccc}
\hline \multirow{2}{*}{ Time } & \multicolumn{7}{c}{ Parameters } \\
& $k_{3}$ & $\alpha_{3}$ & $R^{2}$ & $k_{4}$ & $\alpha_{4}$ & $R^{2}$ \\
\hline 1 & 0.01 & 1.23 & 0.97 & 0.01 & 1.63 & 0.97 \\
3 & 0.01 & 1.21 & 0.99 & 0.01 & 1.60 & 0.99 \\
5 & 0.02 & 1.14 & 0.94 & 0.02 & 1.51 & 0.97 \\
7 & 0.02 & 1.10 & 0.93 & 0.03 & 1.49 & 0.97 \\
9 & 0.03 & 1.05 & 0.93 & 0.03 & 1.49 & 0.96 \\
\hline
\end{tabular}

tamping times. Particularly, the amplitudes at $17 \sim 22 \mathrm{~Hz}$ and $33 \sim 34 \mathrm{~Hz}$ increase greatly when tamping times is beyond 7 . However, these increasing amplitudes are lower than the amplitudes at $6 \sim 10 \mathrm{~Hz}$; in other words, the highest Fourier amplitude is in the range of $6 \sim 10 \mathrm{~Hz}$, which indicates the low frequency vibration in dynamic compaction construction of full-stone foundation.

As seen in Figure 10(b), the spectrum range of vertical vibration is in the range of $5 \sim 50 \mathrm{~Hz}$, and the vibration spectrum also possess two primary frequencies of $6 \sim 8 \mathrm{~Hz}$ and $16 \sim 18 \mathrm{~Hz}$, the amplitude of which increases with the increase of tamping times. It is noted that the amplitude corresponding to the frequency of $16 \sim 18 \mathrm{~Hz}$ is lower than that of the frequency of $6 \sim 8 \mathrm{~Hz}$ within 7 tampings, but this situation is reversed subjected to 9th tamping. Simultaneously, two higher vibration frequency bands $(23 \sim 24 \mathrm{~Hz}$ 


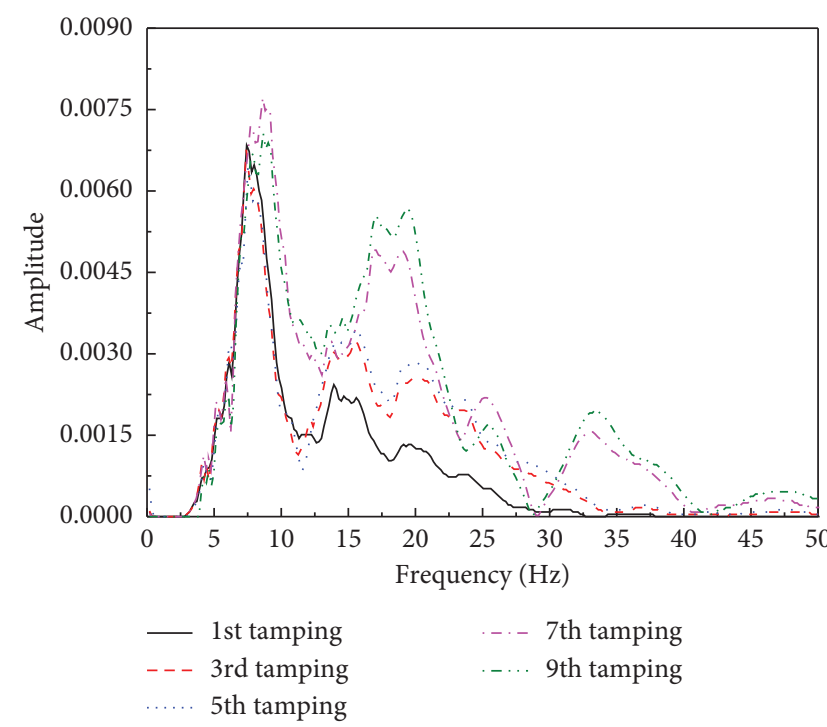

(a)

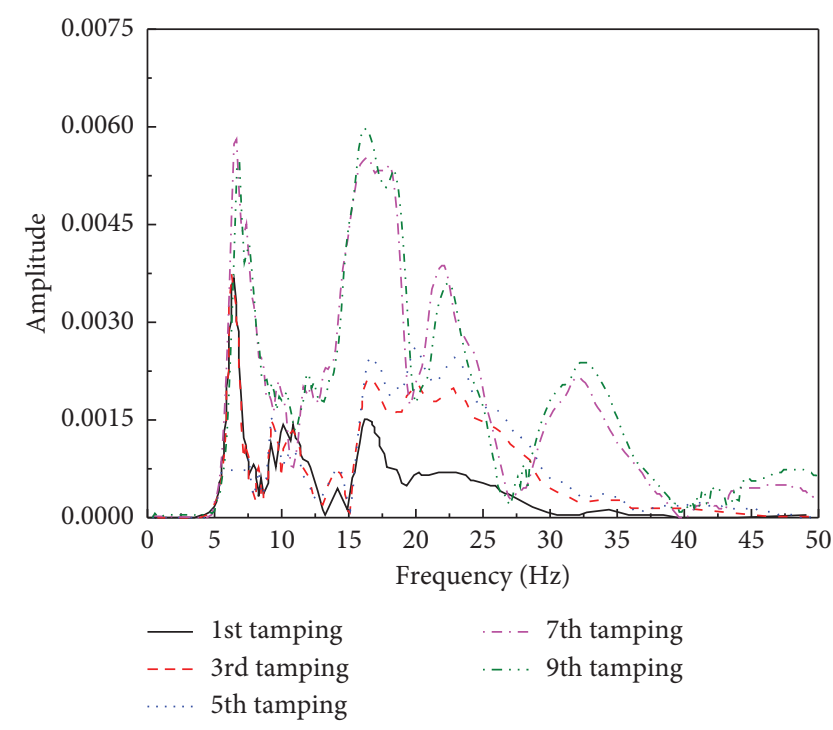

(b)

FIgURe 10: Fourier amplitude spectrum in radial and vertical directions at $80 \mathrm{~m}$ distance. (a) In radial direction. (b) In vertical direction.

and $33 \sim 34 \mathrm{~Hz}$ ) appear in the vertical Fourier spectra as increasing tamping times are beyond 7. Based on the aforementioned data analysis, increasing tamping times can effectively expand the Fourier spectrum frequency range and increase the number of primary frequencies, especially vertical vibration.

It is reported by Hwang and $\mathrm{Tu}$ [14] that the primary frequency of vertical vibration is in the range of $10 \sim 20 \mathrm{~Hz}$, while the radial vibration has two primary frequencies of $3 \sim 4 \mathrm{~Hz}$ and $12 \sim 13 \mathrm{~Hz}$ in a gray silty sand and silty clay foundation. For this full-stone foundation under dynamic compaction, the spectra may have $2 \sim 4$ higher primary frequencies due to lower material damping. Consequently, the Fourier amplitude spectra of ground vibration velocity of the full-stone foundation are featured by multiple primary frequencies and wider frequency band compared to the gray silty sand and silty clay foundation.

4.4.1. Effect of Tamping Time on Vibration Frequency. To comprehensively analyze the law of blasting vibration frequency and to consider the continuity of the propagation process, the average frequency was introduced for describing the spectrum of vibration velocity by Triviño et al. [18]. Average frequency denoted as $f_{c}$ can be calculated as

$$
f_{c}=\frac{\sum_{i=1}^{n} A_{i} f_{i}}{\sum_{i=1}^{n} A_{i}},
$$

where $f_{i}$ represents the individual frequencies in the spectrum $(\mathrm{Hz})$ and $A_{i}$ is the amplitude associated with each frequency $f_{i}$.

The relations between primary frequency, as well as average frequency, and the tamping time are displayed in Figure 11. It can be observed that primary frequencies are

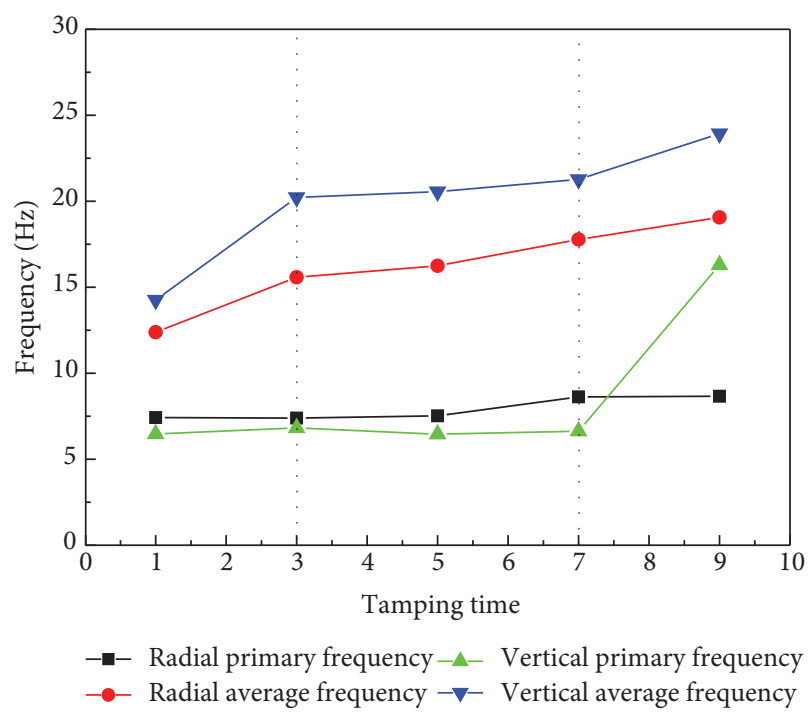

FIGURE 11: Relations between primary and average frequencies and tamping times.

maintained in the range of $6 \sim 9 \mathrm{~Hz}$, except for the vertical primary frequency under the 9 tampings. However, the average frequencies present better positive correlation with tamping times, which matches with the characteristic of Fourier amplitude spectrum influenced by tamping times in Figure 10. Therefore, the average frequency may be used to preferably describe the effect of tamping times and distance on the bulk characteristic of Fourier amplitude.

Figure 12 presents the relations between average frequencies and tamping times at various tamping distances. During the first 4 tampings, the average frequency increases significantly with tamping, with an increased amplitude of $2 \sim 5 \mathrm{~Hz}$. Average frequency at a closer 


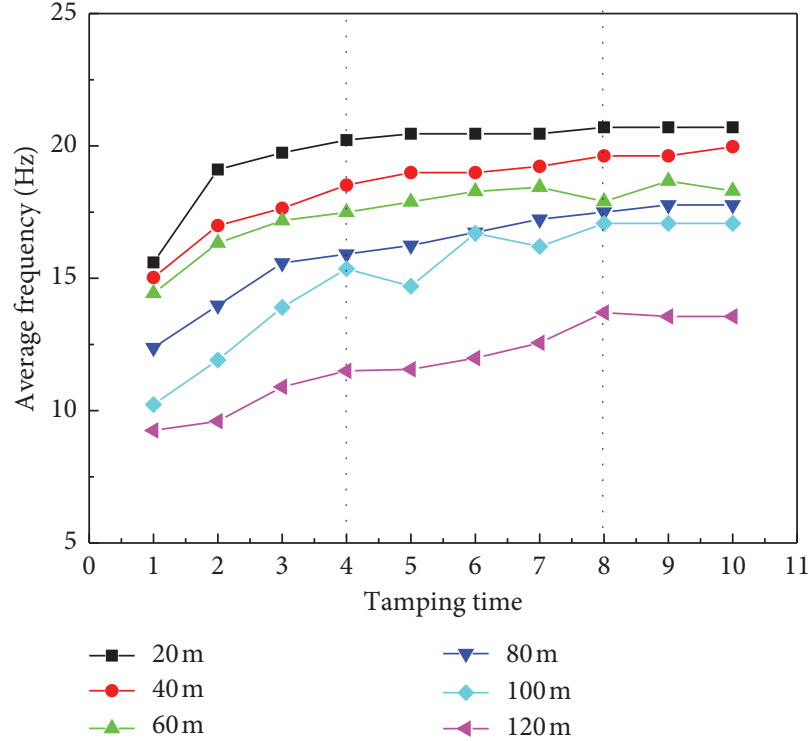

(a)

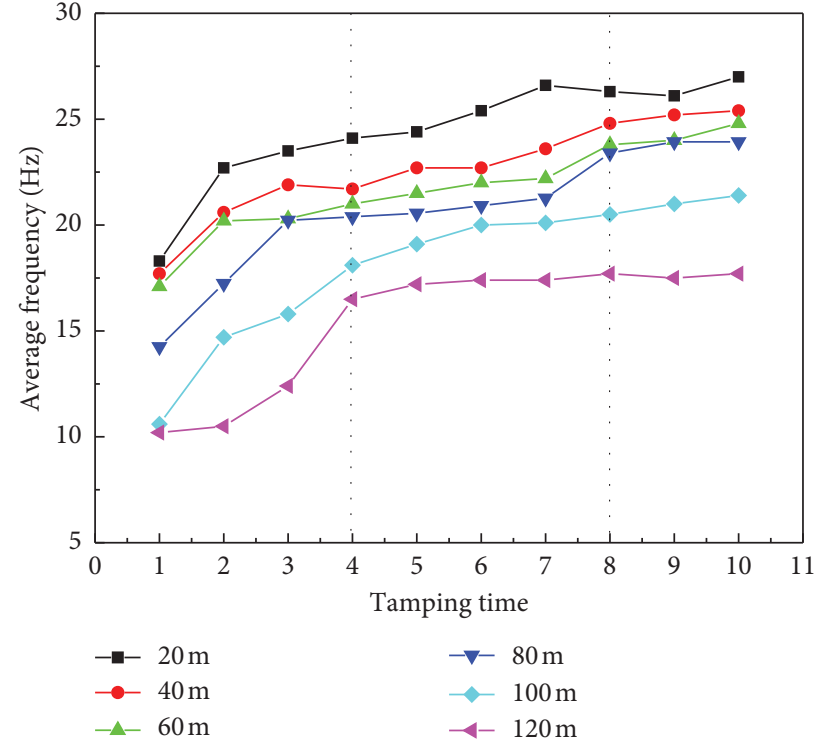

(b)

FiguRE 12: Relations between average frequency and tamping times at different tamping distances. (a) In radial direction. (b) In vertical direction.

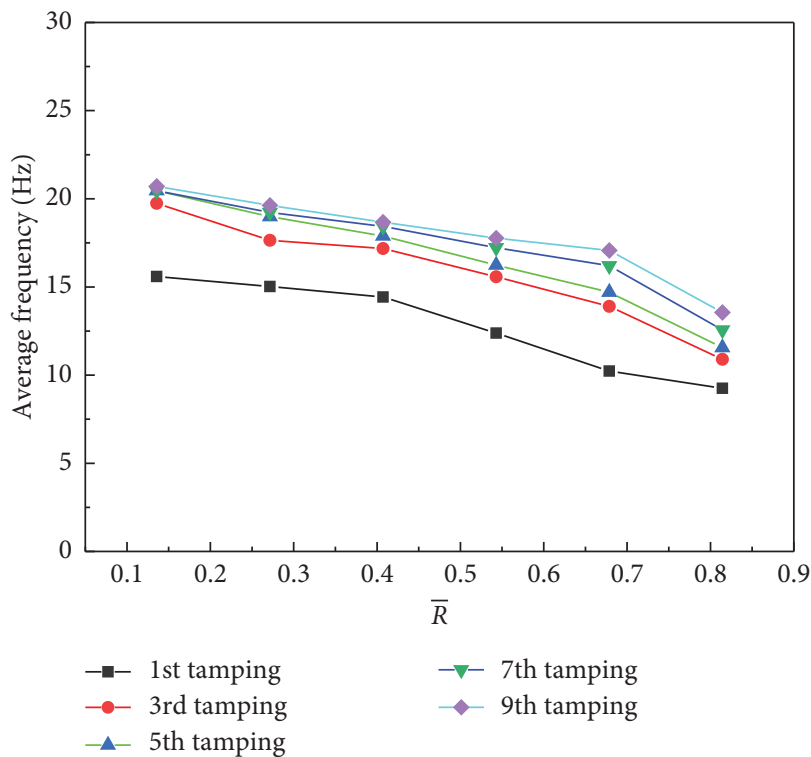

(a)

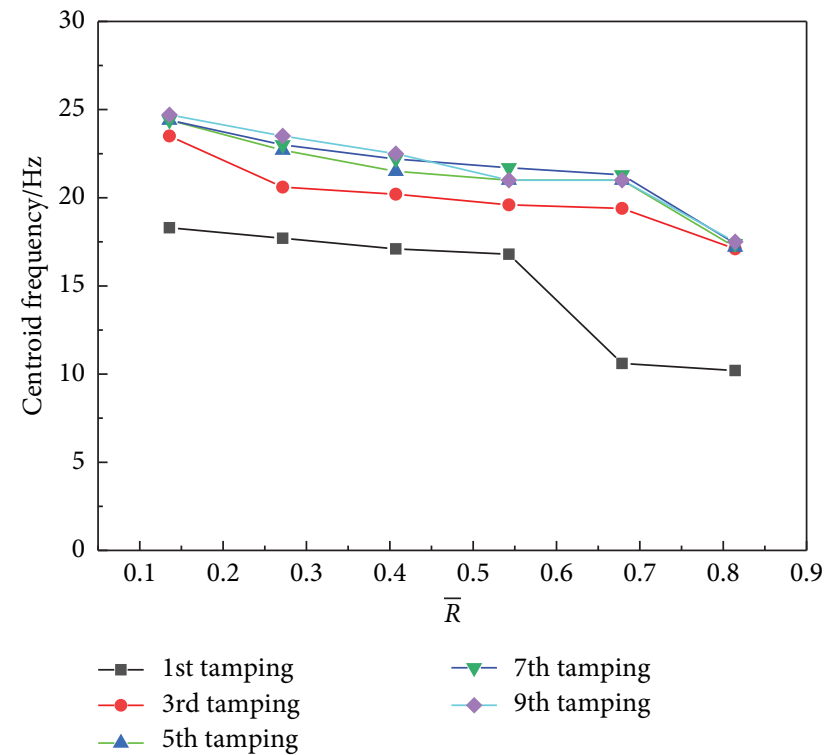

(b)

FIGURE 13: Attenuation of average frequency with distance under different tamping times. (a) In radial direction. (b) In vertical direction.

distance from the tamping point increases more rapidly. At a tamping distance of $20 \mathrm{~m}$, both radial and vertical average frequencies tend to be stable after 4 tampings. More tamping times are needed if the average amplitude is to remain constant at a further location. At a tamping distance of $100 \mathrm{~m}$, the average frequency is stabilized under $4 \sim 8$ tampings. This threshold of tamping times is generally positively correlated with the tamping distance. In other words, the closer the distance, the easier it is for the foundation to stabilize when the foundation is subjected to dynamic compaction.
4.4.2. Effect of Measured Distance on Vibration Frequency. Figure 13 presents the attenuation of both radial and vertical average frequencies with distance under different tamping times. Overall, the average frequency in the vertical direction is greater than that in the radial direction. Apparently, the attenuations of the average frequencies under different tamping times are roughly similar, which decrease linearly with the proportional tamping distance. The attenuation curves of the average frequency are close to each other except for the 1st tamping, which is due to the insufficient dynamic compactness of the full-stone foundation. 


\section{Conclusions}

(1) The ground vibration of the full-stone foundation under a standard tamping energy of $3200 \mathrm{kN} \cdot \mathrm{m}$ lasts approximately $0.75 \sim 1 \mathrm{~s}$, longer than the gray silty sand and silty clay foundation. The duration of radial vibration turns out to be the longest. The radial and vertical waveforms are roughly similar under different times of tamping in each direction.

(2) At $80 \mathrm{~m}$ distance, the Fourier amplitude spectra exhibit a similar shape under different tamping times. The frequency domain of radial vibration mainly ranges from 3 to $42 \mathrm{~Hz}$, which contains two primary frequencies of $6 \sim 10 \mathrm{~Hz}$ and $13 \sim 22 \mathrm{~Hz}$. The frequency domain of vertical vibration ranges from 5 to $50 \mathrm{~Hz}$, which has two primary frequencies of $6 \sim 8 \mathrm{~Hz}$ and $16 \sim 18 \mathrm{~Hz}$. Meanwhile, the amplitudes corresponding to frequencies of $6 \sim 8 \mathrm{~Hz}$ turn to be higher than that of $16 \sim 18 \mathrm{~Hz}$. The frequency spectra exhibit more primary frequencies, higher frequencies, and wider domains with the increase of tamping times. The frequency spectra exhibit more primary frequencies, higher frequencies, and wider domains with the increase of tamping times.

(3) The PGV, PGA, and average frequency of ground vibration first increase significantly with an increase of tamping time, and then remain roughly unchanged due to the compactness of rock foundation. Both PGV and PGA decay with the distance from the tamping point in a negative exponential relation. With the increase of tamping time, the attenuation degree increases correspondingly. Generally, the vibration frequency of the full-stone foundation under dynamic compaction is higher than that of gray silty sand and silty clay foundations, and the average frequency exhibits negative linear correlation with the proportional tamping distance.

\section{Data Availability}

The data used to support the findings of this study are available from the corresponding author upon request.

\section{Conflicts of Interest}

The authors declare that there are no conflicts of interest regarding the publication of this paper.

\section{Acknowledgments}

This research has been supported by the National Natural Sciences Foundation of China (grant nos. 51774295 and 51808551) and the Natural Sciences Foundation of Jiangsu Province (BK20170754).

\section{References}

[1] M. Y. H. Bangash, Impact and Explosion: Analysis and Design, Blackwell, Hoboken, NJ, USA, 1993.
[2] J. Qiao and L. Li, "Model Test Study on vibration transferring of dynamic compaction of hydraulic filling foundation reinforcement," Systems Engineering Procedia, vol. 1, pp. 61-68, 2011.

[3] P. W. Mayne, "Ground vibrations during dynamic compaction," in Proceedings of the Vibration Problems in Geotechnical Engineering, ASCE, Detroit, MI, USA, October 1985.

[4] R. G. Lukas, Geotechnical Engineering Circular No. 1: Dynamic Compaction, Federal Highway Administration, Washington, DC, USA, 1995.

[5] M. Srbulov, Ground Vibration Engineering: Simplified Analyses with Case Studies and Examples, Vol. 12, Springer Science \& Business Media, Berlin, Germany, 2010.

[6] W. I. Duvall and D. E. Fogelson, Review of Criteria for Estimating Damage to Residences from Blasting Vibrations, US Department of the Interior, Bureau of Mines, Washington, DC, USA, 1962.

[7] P. Leger and R. Tremblay, "Earthquake ground motions for seismic damage assessment and re-evaluation of existing buildings and critical facilities," in Damage Assessment and Reconstruction after War or Natural Disaster, pp. 193-219, Springer, Dordrecht, Netherlands, 2009.

[8] T. G. Gutowski and C. L. Dym, "Propagation of ground vibration: a review," Journal of Sound and Vibration, vol. 49, no. 2, pp. 179-193, 1976.

[9] L. Auersch and S. Said, "Attenuation of ground vibrations due to different technical sources," Earthquake Engineering and Engineering Vibration, vol. 9, no. 3, pp. 337-344, 2010.

[10] B. B. Xu, R. Q. Zhang, and L. Y. Guo, "Research of dynamic compaction: a review of recent academic literature," Advanced Materials Research, vol. 1079-1080, pp. 406-409, 2014.

[11] J. K. Mitchell, "Soil improvement-state of the art report," in Proceedings of the Eleventh International Conference on Soil Mechanics and Foundation Engineering, vol. 4, pp. 509-565, San Francisco, CA, USA, August 1985.

[12] W. F. Van Impe, Soil Improvement Techniques and Their Evolution, Balkema, Rotterdam, Netherlands, 1989.

[13] B. Hamidi, N. Hamid, and S. Varaksin, "A case study of vibration monitoring in a dynamic compaction project," in Proceedings of the 14th Asian Regional Conference on Soil Mechanics and Geotechnical Engineering, The Hong Kong Geotechnical Society and The Hong Kong Polytechnic University, Hong Kong, China, May 2011.

[14] J. H. Hwang and T. Y. Tu, "Ground vibration due to dynamic compaction," Soil Dynamics and Earthquake Engineering, vol. 26, no. 5, pp. 337-346, 2006.

[15] M. Lauzon and J.-F. Morel, "Ground vibrations induced by dynamic compaction and rapid impact compaction," in 2011 Pan-Am CGS Geotechnical Conference: 64th Canadian Geotechnical Conference and 14th Pan-American Conference on Soil Mechanics and Geotechnical Engineering, Toronto, Canada, October 2011.

[16] D. Adam, C. Adam, F.-J. Falkner, and I. Paulmichl, "Vibration emission induced by rapid impact compaction," in Proceedings of the 8th International Conference on Structural Dynamics, G. De Roeck, G. Degrande, G. Lombaert, and G. Muller, Eds., pp. 914-921, Leuven, Belgium, July 2011.

[17] J. F. Wiss, "Construction vibrations: state-of-the-art: discussion and closure," Journal of Geotechnical and Geoenvironmental Engineering, vol. 108, no. GT3, 1982.

[18] L. F. Triviño, B. Mohanty, and B. Milkereit, "Seismic waveforms from explosive sources located in boreholes and initiated in different directions," Journal of Applied Geophysics, vol. 87, pp. 81-93, 2012. 


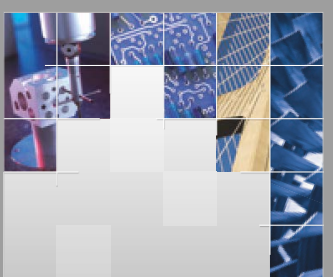

\section{Enfincering}
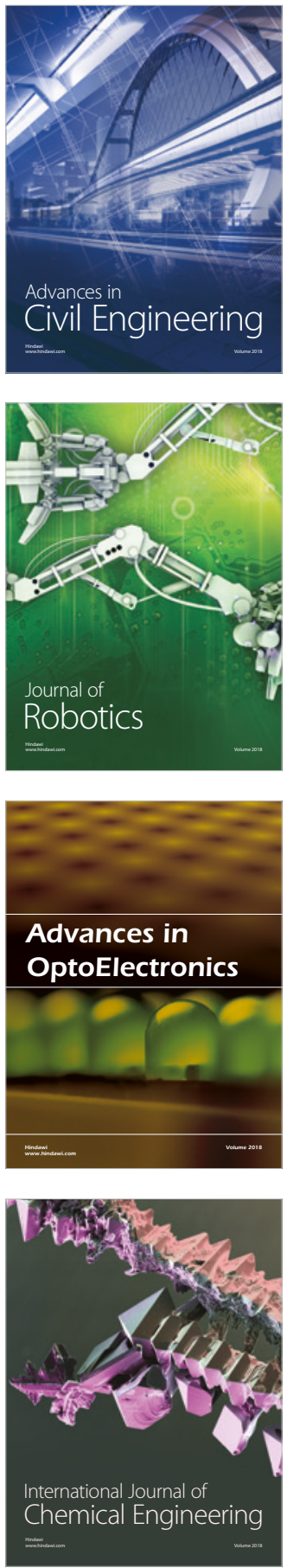

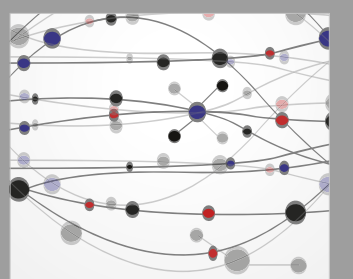

\section{Rotating \\ Machinery}

The Scientific World Journal

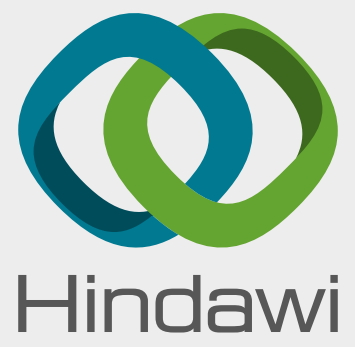

Submit your manuscripts at

www.hindawi.com
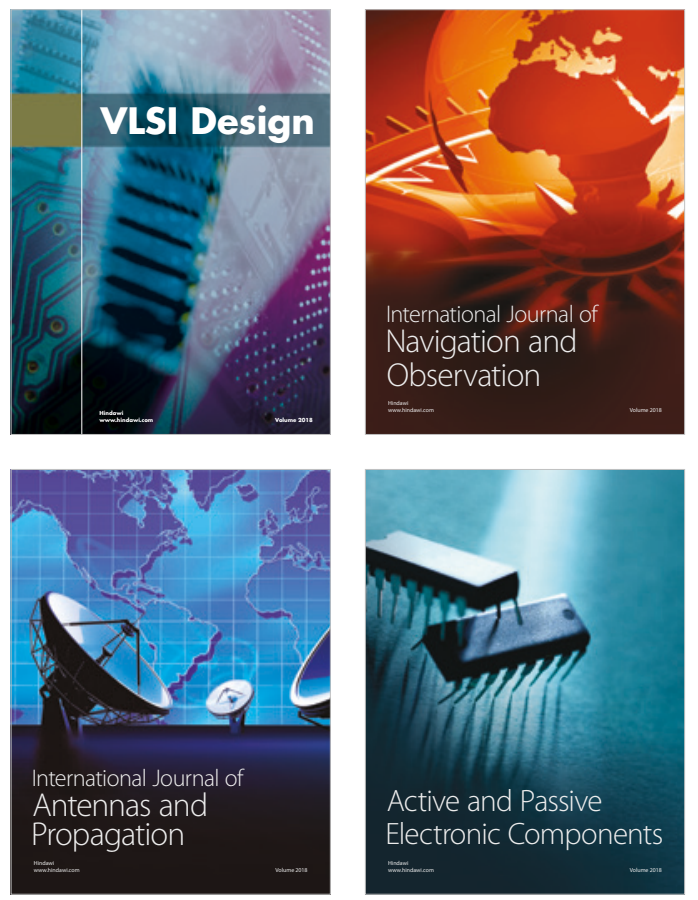
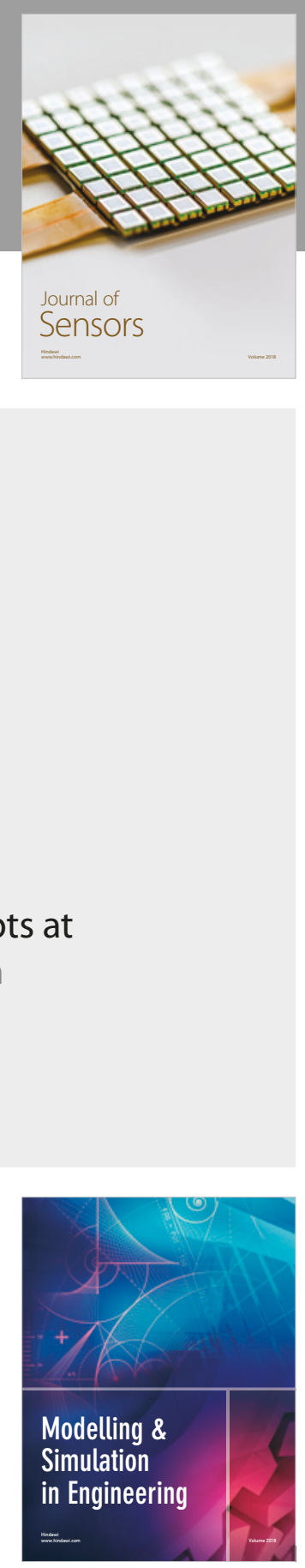

\section{Advances \\ Multimedia}
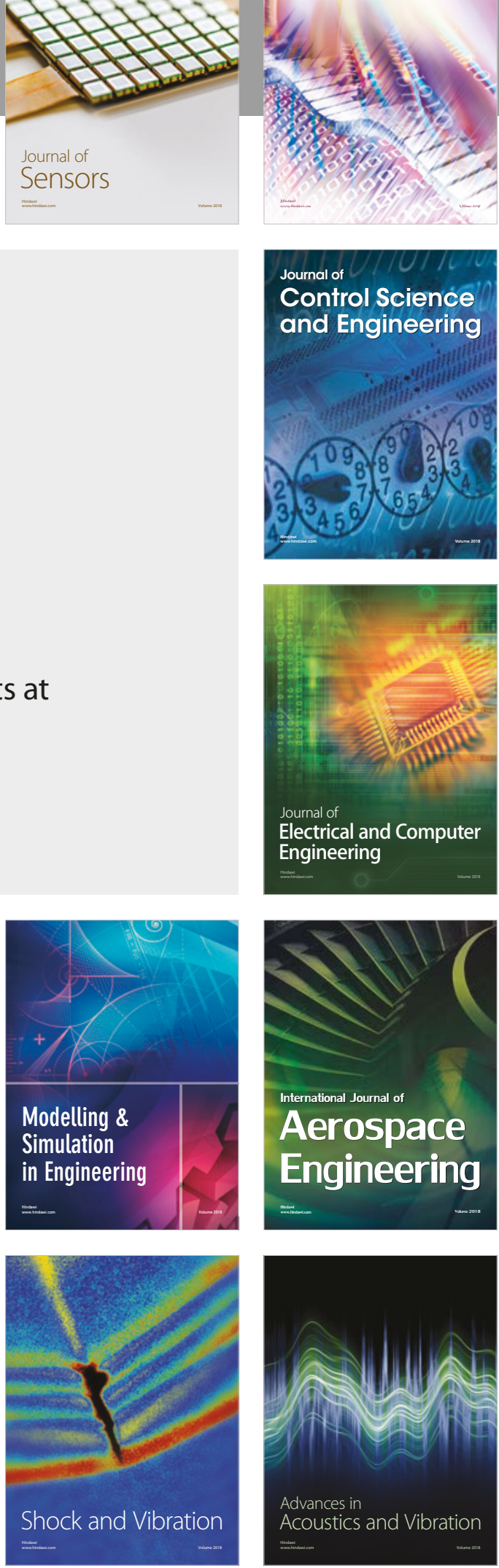